\title{
Patient race, ethnicity, and care in the emergency department: A scoping review
}

\author{
Allison Owens $\odot$, BA Hons ${ }^{*}$; Brian R. Holroyd, MD, MBA ${ }^{\dagger, \neq}$; Patrick McLane, MA, PhD ${ }^{\dagger, \neq}$
}

\section{CLINICIAN'S CAPSULE}

What is known about this topic?

Health disparities between racial and ethnic groups are well documented, and there is evidence these disparities exist in ED care.

What did this study ask?

What is known about the ways ethnicity and/or race impact processes of ED care?

What did this study find?

There is evidence of disparities in waiting times, triage, analgesia, diagnostics, treatment, and patient experiences between racial/ethnic groups.

Why does this study matter to clinicians?

This review allows clinicians to reflect on their practice and facilitates the design of studies and interventions to address disparities.

\section{ABSTRACT}

Objectives: Health disparities between racial and ethnic groups have been documented in Canada, the United States, and Australia. Despite evidence that differences in emergency department (ED) care based on patient race and ethnicity exist, there are no comprehensive literature reviews in this area. The objective of this review is to provide an overview of the literature on the impact of patient ethnicity and race on the processes of ED care.

Methods: A scoping review was conducted to capture the broad nature of the literature. A database search was conducted in MEDLINE/PubMed, EMBASE, CINAHL Plus, Social Sciences Citation Index, SCOPUS, and JSTOR. Five journals and reference lists of included articles were hand searched. Inclusion and exclusion criteria were defined iteratively to ensure literature captured was relevant to our research question. Data were extracted using predetermined variables, and additional extraction variables were added as familiarity with the literature developed.
Results: Searching yielded 1,157 citations, reduced to 153 following removal of duplicates, and title and abstract screening. After full-text screening, 83 articles were included. Included articles report that, in EDs, patient race and ethnicity impact analgesia, triage scores, wait times, treatments, diagnostic procedure utilization, rates of patients leaving without being seen, and patient subjective experiences. Authors of included studies propose a variety of possible causes for these disparities.

Conclusions: Further research on the existence of disparities in care within EDs is warranted to explore the causes behind observed disparities for particular health conditions and population groups in specific contexts.

\section{RÉSUMÉ}

Objectif: II existe bel et bien des différences dans la prestation des soins de santé entre les groupes raciaux et ethniques au Canada, aux États-Unis et en Australie. Bien que des données confirment ces différences fondées sur la race et l'origine ethnique des patients au service des urgences (SU), la documentation en la matière n'a fait l'objet d'aucun examen global. L'étude visait donc à donner un aperçu de la documentation sur l'incidence de l'origine raciale ou ethnique sur la prestation des soins au SU. Méthode: Une analyse documentaire exhaustive a été menée afin de bien saisir le caractère diversifié de la documentation. L'équipe a entrepris une recherche dans les bases de données MEDLINE/PubMed, EMBASE, CINAHL Plus, Social Sciences Citation Index, SCOPUS et JSTOR. Une recherche manuelle a également été effectuée dans cinq revues ainsi que dans les listes de références bibliographiques des articles choisis. Les critères de sélection et d'exclusion ont été établis de manière itérative afin de permettre une recension d'articles liés à la question à l'étude. L'extraction des données s'est faite à I'aide de variables prédéterminées, à quoi se sont ajoutées des variables à mesure que les auteurs acquéraient une meilleure connaissance de la documentation.

Résultats: La recherche documentaire a permis de relever 1157 citations, dont le nombre a été ramené à 153 après l'élimination des doubles et la sélection des titres et des résumés. Finalement,

From the *University of Alberta, Edmonton, AB; ${ }^{\dagger}$ Department of Emergency Medicine, Faculty of Medicine and Dentistry, University of Alberta, University of Alberta Hospital, Edmonton, $A B$; and the ${ }^{\ddagger}$ Emergency Strategic Clinical Network, Alberta Health Services, Edmonton, AB.

Correspondence to: Dr. Patrick McLane; Department of Emergency Medicine, Faculty of Medicine and Dentistry, University of Alberta, 780 University Terrace, 8303112 Street NW Edmonton, Alberta, T6G 1K4; Email: mclane@ualberta.ca

(c) Canadian Association of Emergency Physicians

CJEM 2020;22(2):245-253

DOI 10.1017/cem.2019.458 
83 articles ont été retenus à la suite d'une recherche en texte intégral. Ceux-ci faisaient état de l'incidence de l'origine raciale ou ethnique sur la prestation des soins au SU, notamment sur l'analgésie, les scores de triage, les délais d'attente, les interventions de diagnostic, les traitements, les taux de patients partis sans avoir été vus et l'expérience subjective des patients. Les auteurs des études retenues ont avancé des hypothèses sur les causes possibles de ces écarts.
Conclusion: II faudrait poursuivre la recherche sur l'existence de différences dans la prestation des soins au SU afin d'examiner les causes sous-jacentes aux écarts observés dans des groupes raciaux ou ethniques, relativement à différents problèmes de santé, dans certains contextes.

Keywords: Emergency medicine, public health, aboriginal health

\section{INTRODUCTION}

Disparities in health care between racial and ethnic minority groups compared with whites have been well documented in Canada and the United States. ${ }^{1-3}$ In the United States, disparities in cardiac revascularization and anti-retroviral therapy have been shown to result in higher morbidity and mortality independent of access to care. ${ }^{3}$ In Canada, First Nations people report avoiding care based on experiences of racism. ${ }^{2}$ Racial and ethnic disparities exist when adjusting for socioeconomic status, gender, and other health care related factors. ${ }^{3}$

Disparities have also been documented in emergency care between socioeconomic groups for likelihood of receiving CT scans, ${ }^{4}$ between genders for opioid prescription, ${ }^{5}$ and between races for analgesia in fractures. ${ }^{6,7}$ Such disparities are associated with poorer health outcomes; thus, it is important to identify how race and ethnicity affect emergency care. ${ }^{3}$ The objective of this article is to provide an overview of the literature on how patient ethnicity and race impact processes of emergency department (ED) care. This review will be of use to scholars designing studies on disparities in care or developing interventions to address disparities.

\section{METHODS}

In this scoping review, we synthesize a diverse body of literature to uncover what has been studied related to this topic, how disparities have been explained, and which causes of disparities should be studied further. ${ }^{8,9}$ Arksey and O'Malley describe scoping reviews as a methodology that develops an understanding of the breadth and nature of research surrounding a topic. ${ }^{8}$ Their framework consists of: (1) research question identification, (2) identification of relevant studies, (3) study selection, (4) charting data, and (5) collecting, summarizing, and reporting results. ${ }^{8}$ For steps 4 and 5, we incorporate the suggestion by Levac et al. to adopt qualitative thematic analysis to organize and understand data. ${ }^{9}$

\section{Identification of the research question}

This review is guided by the question: What is known about how ethnicity and/or race impact processes of ED care? Our question is deliberately broad to avoid excluding relevant studies before gaining an understanding of the literature. ${ }^{8}$

\section{Identification of studies}

Inclusion and exclusion criteria were created using the "ECLIPSE" model for structuring search strategies for nonclinical, health care related queries. ${ }^{10}$ See Table 1. We used the model by Asplin et al. of ED crowding to identify processes common to emergency care. ${ }^{11}$ This model conceptualizes three categories of ED processes: input, throughput, and output. We consider throughput processes, which we consider to include everything taking place within the ED. As Asplin et al. note the importance of barriers to care experienced by vulnerable populations, we have included studies on patient experiences. $^{11}$

Literature from the United States, Canada, Australia, New Zealand, and Britain was included. These countries represent Britain and its former colonies, with similar emergency care systems and contemporary white Anglophone majorities. We expected cultural similarities between majority groups in each country to lead to comparable interactions between minority and majority groups. We used Stone and Piya's definition of ethnic groups as "functional units of social organization which consist of members who define themselves, or are defined, by a sense of common historical origins that may also 
Table 1. ECLIPSE Model inclusion criteria

Expectation (improvement or innovation)

Client group (at whom the service is aimed)

Location (where is the service located?)

Impact (outcomes)

Professionals (who is involved in providing/improving the service)

Service (for which service are you looking for information)
This review will uncover the ways other researchers have found ethnicity and race to impact processes of emergency department care

Patients presenting to emergency departments

Canada, Australia, New Zealand, Britain, United States

All processes taking place within the walls of the ED, including but not limited to: triage, wait times, analgesia, diagnostics, treatment, leaving without completing treatment, and patient experiences

Any position working in an emergency department Emergency departments include religious beliefs, a similar language, or a shared culture." 12 We defined race broadly as a socially organized "system of categorization" based on "real or imagined" physical differences/phenotypes. ${ }^{13}$ No time limits were used, and only full-text, English studies were included.

\section{Data sources, search terms, and strategy}

A University of Alberta librarian was consulted for database selection and search strategy development. Searches were performed in 2018 in MEDLINE/PubMed (biomedical sciences, 1946-present), EMBASE, CINAHL Plus, Social Sciences Citation Index, SCOPUS, and JSTOR. Five journals were hand searched; The Canadian Journal of Emergency Medicine, Academic Emergency Medicine, Emergency Medicine Australasia, Emergency Medicine Journal, and Annals of Emergency Medicine. We developed key terms for racial and ethnic groups by identifying populous minority groups in each country. We then trialed additional terms appearing in initial searches to identify whether inclusion of these terms returned additional results, in keeping with Arksey and O'Malley's recommendation that search strategy be iteratively revised as familiarity with literature develops. ${ }^{8}$ Final search query protocol is detailed in the Supplemental Online Appendix A.

\section{Study selection}

Initial screening of titles and abstracts was performed using predetermined inclusion criteria. To refine criteria and ensure that captured articles addressed our research question, the first 100 citations from MEDLINE were screened by two reviewers (A.O., P.M.). ${ }^{9}$ All remaining citations were screened by one reviewer (A.O.). Articles included after title and abstract screening were obtained for full-text screening, completed by one reviewer (A.O.).

\section{Charting of data and summarization of results}

A data extraction form was developed as authors gained familiarity with the literature. ${ }^{9}$ Data extracted included ED process(es) studied, racial/ethnic groups, country, design, year published, control variables, findings, author-proposed explanation of findings, and limitations. Data were compiled into Microsoft Excel for synthesis by one author (AO). Two authors (A.O., P.M.) met throughout extraction to review data and analyze authorproposed causes of disparities thematically. As themes were identified, they were added as fields within the extraction form. Studies were then categorized by ED process studied and cross-tabulated with categories of authors' explanations of disparities.

\section{RESULTS}

The original search yielded 1,157 citations, reduced to 453 after duplicate removal. Of 100 titles and abstracts screened by two reviewers, reviewers agreed on inclusion of 49/100 and exclusion of 41/100. Following discussion, $55 / 100$ were included, and the remaining 45 excluded. Based on this exercise, inclusion criteria were modified to exclude articles on minority group medical literacy, as we determined this was a patient characteristic rather than an ED process. During full-text screening, citations were excluded if they were not full-text articles, focused on reasons for or rates of visiting EDs, were from an excluded country, considered race/ethnicity as a control variable rather than dependent variable, examined outcomes after leaving ED, or did not consider race/ethnicity. Seventy-one citations were included for data 


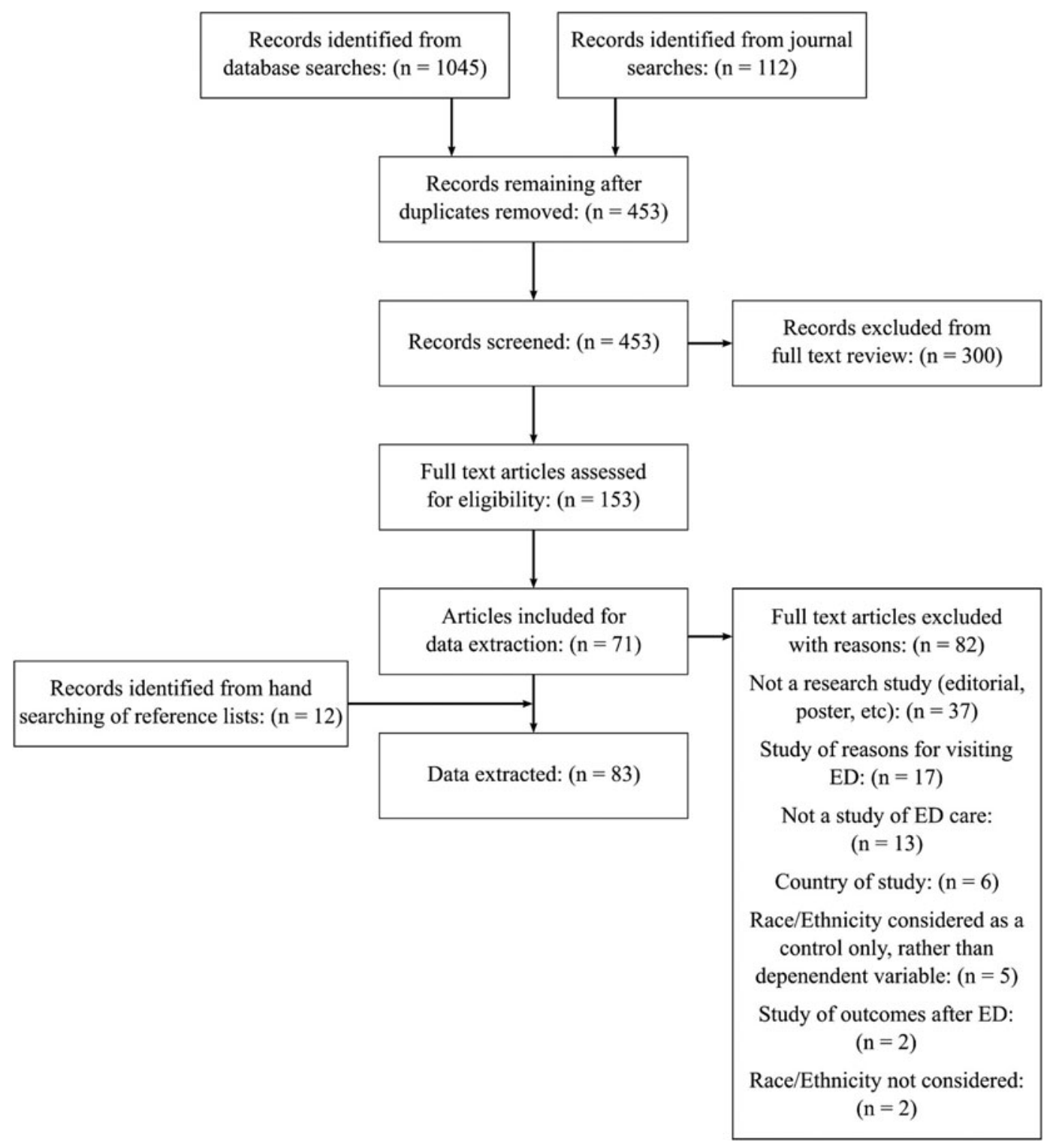

Figure 1. PRISMA flow diagram.

extraction. Reference list searching yielded 12 additional citations. See Figure 1, PRISMA flow diagram.

\section{General characteristics of included articles}

General characteristics of articles are reported in Table 2. Eighty-three articles were published over 28 years, from 1990 to 2018; $68 \%$ of studies were published after 2008. Studies are clustered for analysis by ED process (triage, wait times, analgesia, diagnosis, treatment, leaving without being seen (LWBS)/against medical advice (AMA), and patient experiences). Categories are not mutually exclusive, as some studies report on multiple processes. Citations of all included studies, and notes on findings and methodologies are given in the Supplemental Online Appendix B. See Figure 2 for an analysis of outcomes by study category.

\section{Triage scores}

Seven studies (100\%) considering triage scores found differences between racial and ethnic minority v. majority groups. Six $(86 \%)$ of seven found minority groups had less acute scores, while one (14\%) found that the minority 


\begin{tabular}{|c|c|c|}
\hline Characteristic & $\begin{array}{l}\text { Number } \\
(\mathrm{N}=83)\end{array}$ & $\begin{array}{l}\text { Percentage } \\
(\%)\end{array}$ \\
\hline \multicolumn{3}{|l|}{ Publication year } \\
\hline$<2003$ & 10 & 12.0 \\
\hline 2003-2008 & 16 & 19.3 \\
\hline 2008-2013 & 26 & 31.3 \\
\hline 2013-2018 & 31 & 37.3 \\
\hline \multicolumn{3}{|l|}{ Study design } \\
\hline Retrospective cohort & 13 & 15.7 \\
\hline Retrospective review & 44 & 53.0 \\
\hline Retrospective cross-sections & 1 & 1.2 \\
\hline Prospective cohort & 7 & 8.4 \\
\hline Cross-sectional analysis & 4 & 4.8 \\
\hline Prospective observational & 5 & 6.0 \\
\hline Qualitative measures & 4 & 4.8 \\
\hline Descriptive & 4 & 4.8 \\
\hline Literature review & 1 & 1.2 \\
\hline \multicolumn{3}{|l|}{ Country } \\
\hline Australia & 8 & 9.6 \\
\hline New Zealand & 1 & 1.2 \\
\hline United States & 67 & 80.7 \\
\hline Canada & 3 & 3.6 \\
\hline North America & 3 & 3.6 \\
\hline England & 1 & 1.2 \\
\hline \multicolumn{3}{|l|}{ Throughput variable } \\
\hline Triage/Estimated Severity Score & 7 & 8.4 \\
\hline Waiting Time & 12 & 14.5 \\
\hline LWBS/AMA & 4 & 4.8 \\
\hline Analgesia Disparities & 24 & 28.9 \\
\hline Diagnosis & 20 & 24.1 \\
\hline Treatment & 10 & 12.0 \\
\hline $\begin{array}{l}\text { Reluctance/qualitative } \\
\text { experiences }\end{array}$ & 6 & 7.2 \\
\hline \multicolumn{3}{|l|}{ Race/Ethnicities Considered } \\
\hline African American (AA) & 15 & 18.1 \\
\hline Hispanic & 4 & 4.8 \\
\hline AA + Hispanic & 25 & 30.1 \\
\hline American Indian & 2 & 2.4 \\
\hline First Nations (Canada) & 3 & 3.6 \\
\hline Aboriginal (AUS, NZ) & 8 & 9.6 \\
\hline All & 25 & 30.1 \\
\hline Other & 1 & 1.2 \\
\hline \multicolumn{3}{|l|}{ Providers considered } \\
\hline Nurses & 7 & 8.4 \\
\hline Physicians & 33 & 39.8 \\
\hline All ED staff & 42 & 50.6 \\
\hline Other & 1 & 1.2 \\
\hline
\end{tabular}

group had more acute scores. ${ }^{14-16}$ Some investigators found minority groups had less acute triage scores despite similar presenting complaints or pain ratings. ${ }^{15,17}$

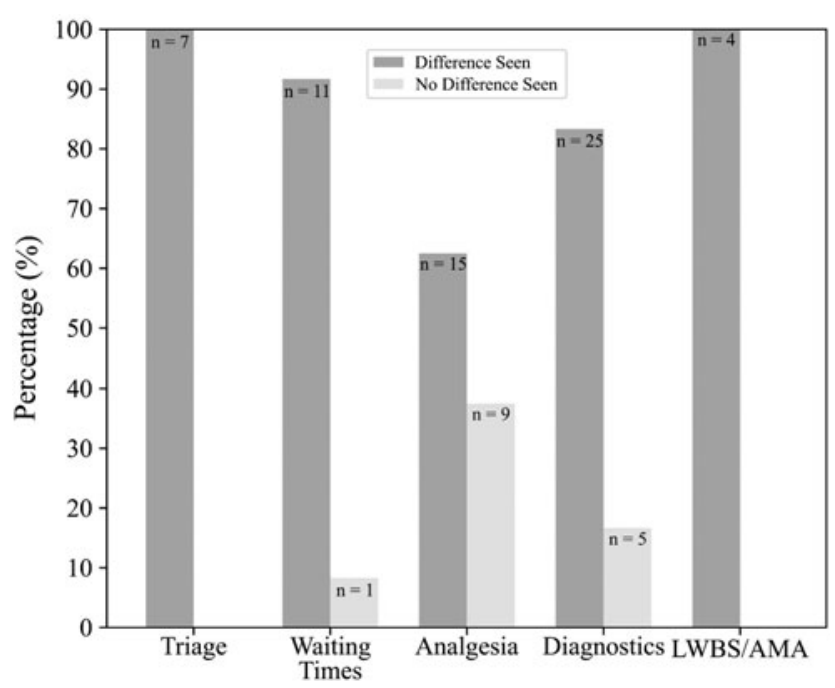

Figure 2. Outcomes by study category.

\section{Waiting times}

Twelve studies examined waiting times. Eleven (91\%) found that minority groups waited longer on average to be assessed than white patients. ${ }^{18}$

\section{Analgesia}

Twenty-four studies examined differences in analgesic administration. Fifteen (63\%) of 24 found differences in analgesic administration between racial and ethnic groups. Six (35\%) of 17 studies found minority group patients were less likely to receive any analgesics compared with the majority group. Eleven (85\%) of 13 studies found that racial/ethnic minority groups were less likely to receive opioids. Three (100\%) of three studies found that racial/ethnic minority groups were less likely to receive a prescription for analgesics. Two (67\%) of three studies found minority groups waited longer for analgesics. Nine (38\%) of 24 studies found no differences between racial and ethnic groups for any process studied.

\section{Diagnostic testing and treatment}

Thirty studies examined differences in diagnostic testing and treatment between racial/ethnic groups. Differences in administration of diagnostic testing and treatment for chest pain, asthma, psychiatric disorders, gastrointestinal complaints, trauma, and strokes were investigated. Twenty-five (83\%) of 30 found differences 
between racial/ethnic minority groups on at least one of the evaluated processes. ${ }^{19-21}$

Studies that found no differences in diagnostics were largely focused on trauma. Five studies examined administration of diagnostic testing in trauma, with four $(80 \%)$ finding no differences. ${ }^{22}$ See Appendix B for details regarding disparities seen in diagnosis and treatment.

\section{LWBS and leaving AMA}

Four (100\%) studies investigating LWBS/AMA found LWBS/AMA more likely in minority group than majority group patients. ${ }^{23,24}$ All focused on Indigenous populations. Harrison et al. found that minority patients other than Indigenous patients were not more likely than their white counterparts to LWBS after controlling for insurance status. ${ }^{23}$ This finding was recently replicated by Weber et al. 2018, in a study published after our search. ${ }^{25}$

\section{Subjective experiences}

Two studies analyzed patient trust in providers. Both found nonwhite patients had lower trust scores for providers than white patients. ${ }^{26,27}$ In qualitative studies of minority patient experiences, themes included discrimination, stereotyping, language barriers, and judgment. ${ }^{28,29}$

\section{Author explanations of causes of disparities}

Using inductive thematic analysis, we categorized explanations of disparities that authors of studies proposed. See Table 3 for definitions of categories. Proposed explanations fall into categories of: (1) provider bias, (2) patient-provider interactions, (3) facility characteristics, (4) clinical presentations, and (5) provider judgement v. standardized care. In some cases, these possible causes appear in the discussion sections of articles, and are not investigated. Authors sometimes cite studies to support proposed explanations of disparities, but it is beyond the scope of this review to follow up on the citations authors relied on.

\section{Provider bias}

Provider biases were suggested as a cause of disparities in analgesia provision, ${ }^{30,31}$ triage scores ${ }^{14,17}$ wait times,${ }^{32,33}$ and patient experiences ${ }^{28}$ in article discussion sections. These author-proposed explanations are based in discussion and do not have supporting data. One study asserted the possibility of overt discrimination as a cause for wait time differences. ${ }^{33}$ Authors finding differences in opioid prescribing suggested that physicians may be more worried about opioid abuse and diversion in certain racial/ ethnic groups. ${ }^{31,34}$

\section{Patient-provider interactions}

Patient-provider interactions were posited to impact analgesia provision, ${ }^{30,35}$ diagnostics, ${ }^{20}$ and patient experiences. ${ }^{26,28}$ Authors proposed that trust for providers may be affected by language barriers, as language differences between providers and patients make it difficult for the patient to articulate their concerns. ${ }^{26,27}$ Another proposed explanation for disparities in trust is a history of discrimination and mistreatment of minority groups. ${ }^{27}$ Authors theorized that patients feel less enabled in decisions about health care when "social distance" is greater between patients and providers. ${ }^{27}$

\section{Facility characteristics}

Characteristics of EDs that minority groups present to were theorized to influence differences in triage scores ${ }^{15}$ and wait times. ${ }^{18}$ Hospitals where minority patients present may be more likely to be in urban centers, serve larger populations, have longer wait times, and have higher average acuity. ${ }^{33}$ Seven studies examined wait times within hospitals compared with between hospitals by race and ethnicity. Five (71\%) of these studies found differences in wait times between races/ethnicities was present both within and between hospitals, suggesting that facility characteristics alone do not explain this disparity. ${ }^{18}$

\section{Differences in clinical presentations}

Numerous authors mention that differences in clinical presentation may impact care. Lower acuity at presentation due to lack of access to primary care was identified as a possible mechanism for differences in $\mathrm{LWBS},{ }^{24}$ wait times, ${ }^{18}$ and diagnostics. ${ }^{20}$ Notably, select studies on wait times ${ }^{32,33}$ and diagnostics ${ }^{19,20}$ found disparities between clinically similar cohorts.

\section{Provider judgment and standardized care}

Analgesia, diagnostics, and treatments received by minority patients were theorized to be impacted by the degree to which care is standardized. ${ }^{22,35,36,37}$ Authors 


\begin{tabular}{|c|c|c|}
\hline $\begin{array}{l}\text { Category of proposed } \\
\text { explanation(s) }\end{array}$ & Definition & $\begin{array}{l}\text { ED processes that study authors } \\
\text { linked to proposed explanations }\end{array}$ \\
\hline Provider bias & $\begin{array}{l}\text { Differences in ED processes between racial or ethnic groups attributed by } \\
\text { study authors to clinician prejudice against the minority racial or ethnic } \\
\text { group(s), or favoritism toward the majority racial or ethnic group. }\end{array}$ & $\begin{array}{l}\text { Analgesia, triage, wait times, } \\
\text { patient experiences }\end{array}$ \\
\hline $\begin{array}{l}\text { Patient-provider } \\
\text { interactions }\end{array}$ & $\begin{array}{l}\text { Differences in ED processes between racial or ethnic groups attributed by } \\
\text { study authors to trust and/or mistrust between patients and providers, ease } \\
\text { or difficulty of communication between patients and providers based } \\
\text { on language or communication style, or patient and provider feelings of } \\
\text { being understood. }\end{array}$ & Analgesia, patient experience \\
\hline Facility characteristics & $\begin{array}{l}\text { In studies of multiple sites, differences in ED processes attributed by study } \\
\text { authors to different population groups tending to present to different } \\
\text { facilities, which may vary in size, characteristics of patient population other } \\
\text { than race or ethnicity, staffing, funding (private v. public), equipment, } \\
\text { busyness, etc. }\end{array}$ & Triage, wait times, diagnoses \\
\hline $\begin{array}{l}\text { Differences in clinical } \\
\text { presentation }\end{array}$ & $\begin{array}{l}\text { Differences in ED processes between racial or ethnic groups attributed by } \\
\text { study authors to variation in medical acuity of patient presentations, and/or } \\
\text { tendency for certain groups to present to ED more frequently. }\end{array}$ & $\begin{array}{l}\text { Triage, wait times, diagnoses, } \\
\text { treatment, leaving without } \\
\text { being seen }\end{array}$ \\
\hline $\begin{array}{l}\text { Provider judgement } \\
\text { v. standardized care }\end{array}$ & $\begin{array}{l}\text { Differences in ED processes between racial or ethnic groups attributed by } \\
\text { study authors to the degree to which care for the specific clinical presentation } \\
\text { has been standardized with order sets, algorithms, or guidelines versus the } \\
\text { degree to which care is subject to provider decision making. }\end{array}$ & Analgesia, diagnoses, treatment \\
\hline
\end{tabular}

found that where provider judgment plays a larger role, disparities in treatment were larger (e.g., analgesic prescribing for "subjective" pain, such as back pain, v. "objective" pain associated with renal calculi). ${ }^{31,37}$ Conversely, authors theorize that a lack of disparities in diagnostics and treatment for trauma patients may be explained by standardization of trauma care, although this was not investigated. ${ }^{22,36}$

\section{DISCUSSION}

\section{Interpretation of findings}

Reviewed literature suggests that minority racial and ethnic groups experience disparities in analgesia, triage scores, wait times, diagnostics, treatments, rates of LWBS/AMA, and subjective experiences in the ED. Author-proposed explanations for disparities consist of: (1) conscious or unconscious bias, (2) patient-provider interactions, (3) facility and resource factors, (4) clinical presentations, and (5) provider judgment v. standardized care.

Authors identified bias, mistrust, language barriers, and social distance as related issues in patient-provider interactions. The fact disparities were noted where provider judgement plays a significant role ${ }^{31,37}$ supports the idea that biases play a role in disparities. Factors such as overcrowding and resource disparities have an impact, but some studies demonstrate disparities between racial and ethnic groups within single hospitals. ${ }^{18}$ Thus, differences between facilities do not necessarily explain disparities in population level studies. ${ }^{18}$ Differences in clinical presentations were theorized to create disparities. However, some studies considering similar clinical cohorts found disparities remained, suggesting that differences in clinical presentation are not the sole cause. ${ }^{19,33}$

\section{Strengths and limitations of this review}

Ethnicity and race specific terms were limited given the tremendous number of ethnic and racial identity categories in use. As we were limited to English, we may have missed relevant articles in other languages. Additionally, thematic analysis involves researcher interpretation of data; thus, it is possible other reviewers may have developed different categories of author explanations for disparities. 


\section{Clinical and research implications}

Many ED processes covered in this review are promising candidates for systematic reviews. Such reviews could focus on specific populations, contexts, or health conditions. Future studies are needed to disentangle issues of bias, patient-provider interactions, facility characteristics, and differences in clinical presentation. Although several studies found disparities in care for racial and ethnic minority groups, overt bias or institutionalized racism was rarely investigated and seldom discussed. ${ }^{18,33}$ Literature on race and ethnicity in ED care is not up to date with evidence and perspectives within public health and social sciences. ${ }^{38,39}$ In particular, the concept of "provider bias" has been critiqued for focusing attention primarily on individual prejudices, and obscuring the way individual prejudices are a product and mechanism of widespread inequities in privileges and access to resources. ${ }^{39}$ Recognition of racism as a systemic problem could bring greater awareness to disparities and allow development of correcting measures.

\section{CONCLUSION}

This scoping review examined the literature on the impact of ethnicity and race on processes of ED care. Findings are mixed, but indicate that further research is needed to explore disparities in analgesia, wait times, triage scores, LWBS/AMA, subjective experiences, treatment, and diagnostics between racial and ethnic groups. Possible causes of these disparities, such as biases, patient-provider interactions, facility characteristics, and differences in clinical presentation, should be investigated in future research.

Financial support: The authors acknowledge the Alberta Health Services Population Public and Indigenous Health Strategic Clinical Network for their support of this project through their 2018 summer studentship award in the amount of $\$ 4500$.

\section{Competing interests: None declared.}

Supplementary material: The supplemental material for this article can be found at https://doi.org/10.1017/cem.2019.458.

\section{REFERENCES}

1. Health Canada. Health determinants for First Nations in Alberta 2016 [Internet]. Alberta (Canada): Government of Canada; 2016 [cited May 18, 2018]. Available at: http://publications.gc.ca/site/archivee-archived.html?url=http://publications.
gc.ca/collections/collection_2016/sc-hc/H34-217-2016-eng. pdf

2. Allan B, Smylie J. First Peoples, second class treatment: the role of racism in the bealth and well-being of Indigenous peoples in Canada [Internet]. Toronto, ON (Canada): The Wellesley Institute; 2015 [cited May 18, 2018]. Available at: https://guides.library. uwa.edu.au/c.php?g=324981\&p=2178452

3. Smedley BD, Stith AY, Nelson AR, edss. Unequal treatment: confronting racial and ethnic disparities in bealth care [Internet]. Institute of Medicine (US) Committee on Understanding and Eliminating Racial and Ethnic Disparities in Health Care. Washington, DC: National Academies Press; 2003 [cited August 22, 2019]. Available at: https://www.ncbi.nlm. nih.gov/books/NBK220358/ doi: 10.17226/12875

4. Bhayana R, Vermeulen MJ, Li Q, Hellings CR, Berdahl C, Schull MJ. Socioeconomic status and the use of computed tomography in the emergency department. Can 7 Emerg Med 2014;16(4):288-95; 10.2310/8000.2013.131102

5. Chen EH. Gender disparity in analgesic treatment of emergency department patients with acute abdominal pain. Acad Emerg Med 2008;15(5):414-8; 10.1111/ j.1553-2712.2008.00100.x

6. Todd KH, Samaroo N, Hoffman JR. Ethnicity as a risk factor for inadequate emergency department analgesia. $7 \mathrm{Am} \mathrm{Med}$ Assoc 1993;269(12):1537-9; 10.1001/jama.269.12.1537

7. Todd KH, Deaton C, D'Adamo AP, Goe L. Ethnicity and analgesic practice. Ann Emerg Med 2000;35(1):11-6; 10.1016/S0196-0644(00)70099-0

8. Arksey H, O'Malley L. Scoping studies: towards a methodological framework. Int 7 Soc Res Method 2005;8(1):19-32; $10.1080 / 1364557032000119616$

9. Levac D, Colquhoun H, O'Brien KK. Scoping studies: advancing the methodology. Implement Sci 2010;5:69-77; 10.1186/1748-5908-5-69

10. Wildridge V, Bell L. How clip became eclipse: a mnemonic to assist in searching for health policy/management information. Health Info Libr fournal 2002;19(2):113-5; 10.1046/ j.1471-1842.2002.00378.x

11. Asplin BR, Magid DJ, Rhodes KV, Solberg LI, Lurie N, Camargo CA. A conceptual model of emergency department crowding. Ann Emerg Med 2003;42(2):173-80; 10.1067/ mem.2003.302

12. Stone J, Piya B. Ethnic Groups. In: The Blackwell Encyclopedia of Sociology [Internet]. New York: John Wiley \& Sons; 2007 [cited August 22, 2019]; 10.1002/9781405165518.wbeose064

13. Lemonik-Arthur MM. Race. In: The Blackwell Encyclopedia of Sociology [Internet]. New York: John Wiley \& Sons; 2007 [cited August 22, 2019]; 10.1002/9781405165518.wbeosr001

14. Vigil JM, Alcock J, Coulombe P, et al. Ethnic disparities in emergency severity index scores among U.S. veteran's affairs emergency department patients. PLoS One 2015;10(5):1-10; 10.1371/journal.pone.0126792

15. Lopez L, Wilper AP, Cervantes MC, Betancourt JR, Green AR. Racial and sex differences in emergency department triage assessment and test ordering for chest pain, 1997-2006. Acad Emerg Med 2010;17(8):801-8; 10.1111/ j.1553-2712.2010.00823.x

16. Johnston-Leek M, Spirvulis P, Stella J, Palmer D. Emergency department triage of Indigenous and non-Indigenous 
patients in tropical Australia. Emerg Med 2001;13(3):333-7; 10.1046/j.1035-6851.2001.00237.x

17. Vigil JM, Coulombe P, Alcock J, et al. Patient ethnicity affects triage assessments and patient prioritization in U.S. Department of Veterans affairs emergency departments. Medicine 2016;95(14):1-7; 10.1097/MD.0000000000003191

18. Sonnenfeld N, Pitts SR, Schappert SM, Decker SL. Emergency department volume and racial and ethnic differences in waiting times in the United States. Med Care 2012;50 (4):335-41; 10.1097/MLR.0b013e318245a53c

19. Pezzin LE, Keyl PM, Green GB. Disparities in the emergency department evaluation of chest pain patients. Acad Emerg Med 2007;14(2):149-56; 10.1197/j.aem.2006.08.020/abstract

20. Levas MN, Dayan PS, Mittal MK, et al. Original article: effect of Hispanic ethnicity and language barriers on appendiceal perforation rates and imaging in children. 7 Pediatr 2014;164(6):1286-91; 10.1016/j.jpeds.2014.01.006

21. Payne NR, Puumala SE. Racial disparities in ordering laboratory and radiology tests for pediatric patients in the emergency department. Pediatr Emerg Care 2013;29(5):598606; 10.1097/PEC.0b013e31828e6489

22. Shafi S, Gentilello LM. Ethnic disparities in initial management of trauma patients in a nationwide sample of emergency department visits. Arch Surg 2008;143(11):1057-61; 10.1001/archsurg.143.11.1057

23. Harrison B, Finkelstein M, Puumala S, Payne NR. The complex association of race and leaving the pediatric emergency department without being seen by a physician. Pediatr Emerg Care 2012;28(11):1136-45; 10.1097/PEC.0b013e31827134db

24. Wright L. "They just don't like to wait"-A comparative study of Aboriginal and non-Aboriginal people who did not wait for treatment, or discharged themselves against medical advice from rural emergency departments: part 2. Aust Emerg Nursing 7 2009;12(3):93-103; 10.1016/ j.aenj.2009.05.002

25. Weber TL, Ziegler KM, Kharbanda AB, Payne NR, Birger C, Puumala SE. Leaving the emergency department without complete care: disparities in American Indian Children. BMC Health Serv Res 2018;18(267):1-6; /10.1186/ s12913-018-3092-z

26. Fields A, Abraham M, Gaughan J, Haines C, Hoehn KS. Language matters: race, trust, and outcomes in the pediatric emergency department. Pediatr Emerg Care 2016;32(4):222-6; 10.1097/PEC.0000000000000453

27. Lee JS, Tamayo-Sarver J, Kinneer P, Hobgood C. Association between patient race/ethnicity and perceived interpersonal aspects of care in the emergency department. $7 \mathrm{Natl}$
Med Assoc 2008;100(1):79-85; 10.1016/S0027-9684(15) 31179-2

28. Pickner WJ, Ziegler KM, Hanson JD, et al. Community perspectives on emergency department use and care for American Indian children. 7 Racial Ethn Health Disparities 2017;5 (5):939-46; 10.1007/s40615-017-0442-1

29. Chapman R, Smith T, Martin C. Qualitative exploration of the perceived barriers and enablers to Aboriginal and Torres Strait islander people accessing healthcare through one Victorian emergency department. Contemp Nurse 2014;48(1):48-58; 10.5172/conu.2014.48.1.48

30. Pletcher MJ, Kertesz SG, Kohn MA, Gonzales R. Trends in opioid prescribing by race/ethnicity for patients seeking care in US emergency departments. $7 A M A$ 2008;299(1):70-8; 10.1001/jama.2007.64

31. Singhal A, Tien YY, Hsia RY. Racial-ethnic disparities in opioid prescriptions at emergency department visits for conditions commonly associated with prescription drug abuse. PLoS One 2016;11(8);e0159224; 10.1371/journal.pone.0159224

32. Haywood Jr C, Tanabe P, Naik R, Beach MC, Lanzkron S. The impact of race and disease on sickle cell patient wait times in the emergency department. Am 7 Emerg Med 2013;31(4):651-6; 10.1016/j.ajem.2012.11.005

33. James CA, Bourgeois FT, Shannon MW. Association of race/ ethnicity with emergency department wait times. Pediatrics 2005;115(3):310; 115/3/e310

34. Joynt M, Train MK, Robbins BW, Halterman JS, Caiola E, Fortuna RJ. The impact of neighborhood socioeconomic status and race on the prescribing of opioids in emergency departments throughout the United States. 7 Gen Intern Med 2013;28(12):1604-10; 10.1007/s11606-013-2516-z

35. Ortega HW, Velden HV, Lin C, Reid S. Race, ethnicity, and analgesia provision at discharge among children with longbone fractures requiring emergency care. Pediatr Emerg Care 2013;29(4):492-7; 10.1097/PEC.0b013e31828a34a8

36. Bazarian JJ, Pope C, McClung J, Cheng YT, Flesher W. Ethnic and racial disparities in emergency department care for mild traumatic brain injury. Acad Emerg Med 2003;10 (11):1209-17; 10.1197/S1069-6563\%2803\%2900491-3

37. Dickason RM, Chauhan V, Mor A, et al. Racial differences in opiate administration for pain relief at an academic emergency department. West 7 Emerg Med 2015;16(3):372-80; 10.5811/westjem.2015.3.23893

38. Jones CP. Confronting Institutionalized Racism. Phylon 2002;50(1/2):7-22; doi:10.2307/4149999

39. Feagin J, Bennefield J. Systemic racism and US health care. Soc Sci Med 2014;103:7-14; 10.1016/j.socscimed.2013.09.006 